Article

\title{
Experimental Determination of the Heat Transfer Coefficient of Real Cooled Geometry Using Linear Regression Method
}

\author{
Asif Ali *(D), Lorenzo Cocchi $(D$, Alessio Picchi $(D)$ and Bruno Facchini \\ DIEF Department of Industrial Engineering, University of Florence, Via Santa Marta 3, 50132 Florence, Italy; \\ lorenzo.cocchi@htc.unifi.it (L.C.); alessio.picchi@htc.unifi.it (A.P.); bruno.facchini@htc.unifi.it (B.F.) \\ * Correspondence: asif.ali@unifi.it; Tel.: +39-055-2758715
}

Citation: Ali, A.; Cocchi, L.;

Picchi, A.; Facchini, B. Experimental

Determination of the Heat Transfer Coefficient of Real Cooled Geometry Using Linear Regression Method. Energies 2021, 14, 180.

https://doi.org/10.3390/en14010180

Received: 12 November 2020 Accepted: 24 December 2020 Published: 31 December 2020

Publisher's Note: MDPI stays neutral with regard to jurisdictional clai$\mathrm{ms}$ in published maps and institutional affiliations.

Copyright: (C) 2020 by the authors. Licensee MDPI, Basel, Switzerland. This article is an open access article distributed under the terms and conditions of the Creative Commons Attribution (CC BY) license (https:// creativecommons.org/licenses/by/ $4.0 /)$.

\begin{abstract}
The scope of this work was to develop a technique based on the regression method and apply it on a real cooled geometry for measuring its internal heat transfer distribution. The proposed methodology is based upon an already available literature approach. For implementation of the methodology, the geometry is initially heated to a known steady temperature, followed by thermal transient, induced by injection of ambient air to its internal cooling system. During the thermal transient, external surface temperature of the geometry is recorded with the help of infrared camera. Then, a numerical procedure based upon a series of transient finite element analyses of the geometry is applied by using the obtained experimental data. The total test duration is divided into time steps, during which the heat flux on the internal surface is iteratively updated to target the measured external surface temperature. The final procured heat flux and internal surface temperature data of each time step is used to find the convective heat transfer coefficient via linear regression. This methodology is successfully implemented on three geometries: a circular duct, a blade with U-bend internal channel, and a cooled high pressure vane of real engine, with the help of a test rig developed at the University of Florence, Italy. The results are compared with the ones retrieved with similar approach available in the open literature, and the pros and cons of both methodologies are discussed in detail for each geometry.
\end{abstract}

Keywords: internal heat transfer; real hardware; regression; IR thermography; thermal transient technique

\section{Background}

Gas turbine efficiency and power output is limited by the extreme temperature encountered in the high-pressure turbine. To combat this condition, different gas turbine components (e.g., blade) are cooled with different cooling schemes using air which is drawn from the compressor. It is important that the cooling air is employed efficiently by the cooling system, since this mass flow rate is removed from the main flow, and, thus, the engine power output and efficiency are reduced. The cooling scheme must be designed in such a way that it maximizes the internal convective heat transfer and minimizes the pressure loss of the moving fluid. This can be achieved by introducing different cooling configurations, like ribs, pins, dimples, and impingement jets in the cooling scheme. The details about these cooling enhancement configurations and their development can be reviewed in the books by Han [1,2] and Webb [3].

Heat transfer distribution measurement of any cooling scheme of a gas turbine component is a direct assessment of its functionality, as well as its suitability. The advancement of different cooling enhancement configurations and improved manufacturing methods have increased the complexity of cooling schemes and made the internal heat transfer distribution strongly 3D in nature and difficult to predict; moreover, in some configurations, real hardware aspects, such as roughness, manufacturing tolerances (e.g., of cooling holes), and defects, play a crucial role [4]. As a result, in order to measure this heat transfer distribution, more detailed and reliable experimental techniques are required. While working 
with real hardware, these techniques are essential in a preliminary design phase in which different cooling strategies can be compared or in the production phase in which heat transfer variance respect to engine condition can be highlighted.

Already available experimental techniques used for this purpose, but, limited to models of engine components mainly manufactured in low thermal conductivity material, are thermochromic liquid crystal (TLC), infared (IR) thermography, heating foils combined with thermocouples, and sublimation. Von Wolfersdorf and Weigand [5] reviewed the detailed analysis of different experimental approaches. In most of these techniques, a scaled model of the actual significant portion of the engine component is used for investigation purposes. Moreover, to obtain high resolution results, enlarged scale models are used, which operate close to ambient temperature in order to overcome measurement apparatus constraints. However, using scaled models, some important features may be lost or become hard to predict, i.e., surface roughness, deviation from the ideal geometry, whole system interaction, and others. These issues can be solved by considering real hardware for investigation purposes. Werschnik et al. [6] designed a test rig which resembles the higher pressure turbine to study the effect of combustor swirl on endwall on heat transfer and film cooling effectiveness. At the Oxford turbine research facility, a combustor swirl simulator (at engine scale) was designed for studying the influence of the swirl on the higher pressure turbine stage [7]. However, this approach also has strong limitations faced by many authors, in terms of smaller size of the component, difficulty in accessing the inner surface of the geometry, and higher conductivity of the material, which smooths the temperature patterns related to the internal heat transfer distributions.

A standard approach used by many authors to measure the heat transfer distribution consists of inducing a controlled thermal transient inside the investigatory geometry by injecting a cooling medium from a known thermal state at a given initial time $(t=0)$. During the thermal transient phenomenon, the external surface temperature evolution is recorded with help of thermal imaging techniques, which can be used for qualitative or quantitative assessment of the internal cooling scheme. Bantel and Mack [8] were the first ones to use this approach in which a hot gas was forced to pass through a channel and then the transient response of the channel was recorded by an IR camera. Bantel further extended it for quantitative evaluation of defects in gas turbine blade [9]. Carl et al. [10] and Stiglich et al. [11] used quartz lamp for heating purpose and then introduced a coolant to induce a transient response, in order to retrieve information about the internal heat transfer distribution of gas turbine airfoils. In both of these works, the thermal output was compared to a known standard to evaluate the heat transfer distribution in an indirect way. Nirmalan et al. [12] introduced an iterative inverse conduction scheme by running finite element model (FEM) of the geometry with the aim to replicate the measured experimental thermal transient. The scheme was implemented on a metallic airfoil for measuring its heat transfer distribution, which will be the one providing the same external surface temperature in both experimental and FEM analysis. To speed up the convergence rate of the procedure, the first attempted heat transfer distribution was obtained by using lumped thermal capacitance model (LTCM). The authors considered a constant coolant temperature in this case but suggested to use a proper fluid model to evaluate local time-varying flow temperature for more complex geometries. This technique was further used for assessing the flow feature of film holes by comparing the obtained results with a standard [13].

Heidrich et al. [14] and Egger et al. [15] used a enhanced LTCM which is capable of taking into account the lateral conduction and external heat losses. A full 3D similar approach was also employed by Christensen and Mathison [16] to a straight duct with different inlet geometries for obtaining its cooling features.

The above short review highlights the growing interest in the investigation of real engine components, which could both overcome the limitations of the enlarged scale tests and be useful for quality assessment purposes. This work fits with this research trend, since it presents the development and implementation of a procedure to measure heat transfer distribution of real geometries. 


\section{Proposed Methodology}

The main objective of the methodology is to measure the internal heat transfer distribution of a real cooled geometry. The basic principle of the technique consists of forcing the internal heat transfer to induce a thermal transient inside the geometry. Subsequently, a numerical simulation of this phenomenon is set up, and the required internal heat transfer distribution of the geometry will be the one which makes the simulation to behave as the experiment. The proposed methodology is the modified version of the technique firstly proposed by Nirmalan et al. [12]. It consists of two separate steps, the first being an experimental one and the second a numerical one (finite element analysis).

\subsection{Experimental Part}

The proposed methodology begins with placing a desired geometry on a test stand for which we want to measure the internal heat transfer. Next, a controlled thermal transient is induced by injecting a coolant into the geometry which is preheated to a desired thermal state. For having a controlled thermal transient, the initial desired temperature distribution of the whole geometry is known, heat source value is known everywhere, and the coolant temperature and mass flow rate is constant. It is necessary that the initial desired thermal state allows the attainment of the overall temperature distribution of the geometry. This can be achieved by running preconditioning phase until a steady thermal state is obtained, so that the initial temperature of the geometry is either uniform or can be retrieved easily, i.e., through a steady finite element analysis. Coolant temperature considered in this case is ambient but can be varied in order to affect the internal heat flux and, thus, to control the test duration.

During the thermal transient, the external surface temperature evolution of the geometry is recorded. A thermal imaging technique, like thermochromic liquid crystal or IR imaging, will be required for geometry spatial resolved temperature distribution. The selection of technique depends upon the test temperature range, accuracy, and geometry. IR technique is recommended for studying a complex 3D geometry operating in high temperature environments because of its ability to handle larger temperature range and low sensitivity to the viewing angle [17], given that the geometry measuring surface is properly treated.

\subsubsection{Test Rig}

A test rig was installed in the Heat Transfer and Combustion Lab of the Department of Industrial Engineering, University of Florence (DIEF) to implement the experimental part of the procedure. The schematic of the test rig is shown in the Figure 1a, while Figure $1 b, c$ show the pictures of the assembly. The geometry to be investigated is installed on a dedicated stand, designed in order to support it mechanically and, if required, to provide leakage proof hydraulic connection with the coolant supply system. In particular, all connections between the test sample and the stand are made of PTFE inserts, in order to thermally insulate the sample and, thus, reduce the spurious conductive heat fluxes to negligible values.

An electric oven is employed to heat the geometry to a desired thermal state. Inside the oven, 10 ceramic heaters are housed, each one capable of providing power of $325 \mathrm{~W}$ (Figure 1c) and fed by a $4.8 \mathrm{kVA}$ electric transformer with the possibility to regulate the output voltage. For full exposure of the geometry external surface to the IR camera during the heating phase, the oven is provided with locks and a rail support which helps it to move away from the geometry after the heating phase. For the same reason, the oven has a pliers-like design: the heaters are installed on the two semi-cylindrical shutters, which can be closed manually to embrace the geometry during the heating part or opened to expose it to IR camera during the thermal transient. 


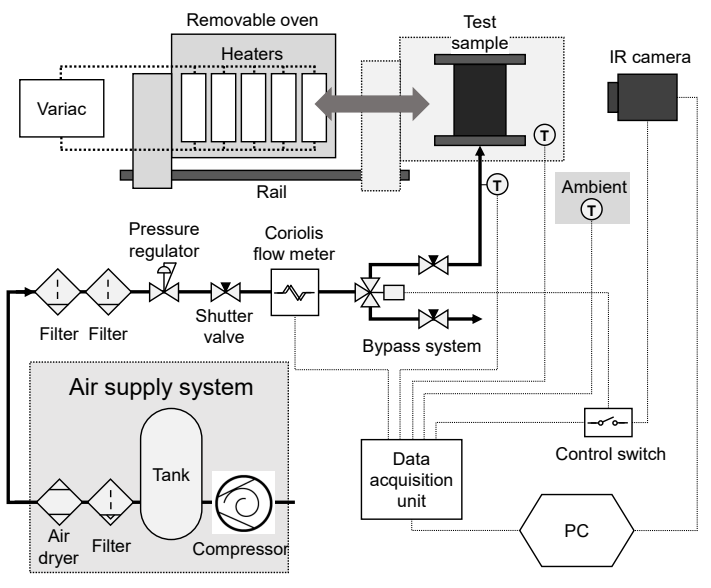

(a)

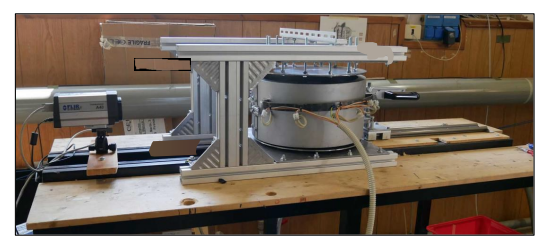

(b)

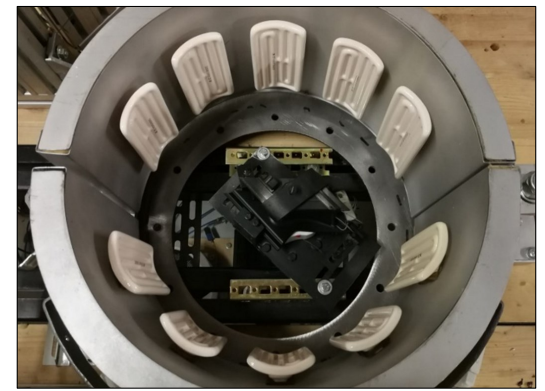

(c)

Figure 1. Schematic of the Test rig. (a) Test rig overall assembly. (b) Geometry inside the oven (c).

After completing the heating phase, to achieve a thermal transient, a coolant must flow to the geometry cooling channel. For this purpose, a suitable air supply system is used which is capable of providing up to $40 \mathrm{~g} / \mathrm{s}$ of dry air at 8 bar, as shown in Figure 1a. The air supply system is provided with a filtering section and a pressure regulator for achieving uncontaminated flow with constant pressure during the test. A shutter valve helps in regulating the mass flow rate, which is measured by Coriolis flow meter (Bronkhorst CORI-FLOW ${ }^{\mathrm{TM}} \mathrm{M} 55,12 \mathrm{~g} / \mathrm{s}$ range, $0.5 \%$ accuracy). The bypass system is employed to avoid sudden mass flow variation at the beginning of the test for air supply and measurement system. The bypass system feeding line is split into two branches by means of an actuated 3-way valve: one branch is connected with test sample, while the other bypasses air to the laboratory atmosphere. Each branch is provided with a shutter valve, set in such a way that the total head loss of the bypass line is the same as the one which is connected to the geometry sample including the sample itself. In this way, it is possible to set up the desired flow conditions before the test by flowing air through the bypass line. A 3-way valve is connected with a switch: by closing the switch, the valve is activated to direct the flow towards the geometry without causing any mass flow variation for the upstream system.

Each test geometry is positioned inside the oven with the help of dedicated support with screws and is connected to the air supply line. To have more accurate temperature measurement and higher surface emissivity, the external surface of the geometry is painted with a high temperature resistant black paint. In particular, for the present test campaign, six layers of paint were applied to the outer surface of the geometries, in order to ensure a complete coverage and, thus, a uniform emissivity even for complex and fully 3D surfaces. The calibration of the emissivity of the used paint is performed with the help of a flat aluminium sample, painted on one side, while heated by film heater on the other side. Emissivity values are retrieved by targeting the temperature reading of the IR camera with the measurement of a thermocouple embedded in the sample. The calibration sample was sprayed in the same painting session as the geometries and using the same number of paint layers.

During the thermal transient, the geometry external surface and coolant temperature will be measured by a data acquisition system, consisting of IR camera, thermocouples, data acquisition unit, and PC. In the case of vane or blade testing, one IR camera and two mirrors will be required to retrieve a full external surface temperature distribution. The leading edge (LE) of the vane or blade is observed by IR directly, while the pressure side (PS) and suction side (SS) will be seen through mirrors. The mirrors are made of PMMA smooth plates deposited with a thin aluminium layer. The use of mirror does not add up 
any variation in the measurement, which was demonstrated with the help of the already mentioned paint calibration device.

A FLIR ThermoVision ${ }^{\mathrm{TM}}$ A40 IR camera, equipped with Focal Plane Array (FPA) uncooled microbolometer with accuracy of $2 \mathrm{~K}$, is used for the recording the surface temperature of $240 \times 320$ points at frequency of $25 \mathrm{~Hz}$. Two thermocouples (type T) measure the coolant temperature at the upstream cooling channel inlet of the geometry with an accuracy of $0.5 \mathrm{~K}$. Thermocouples are also used for monitoring the temperature inside the oven at various places during the heating phase, as well as to measure the ambient temperature. All the thermocouples are connected to a data acquisition/switch unit (Agilent 34970A) and to a temperature controlled cold junction (Pt100, $0.1 \mathrm{~K}$ absolute accuracy).

\subsubsection{Experimental Procedure Steps}

- The first step is the heating of the geometry inside the oven until its temperature reaches to a desired target temperature of $230{ }^{\circ} \mathrm{C}$ and becomes constant. During the heating phase the temperature inside the oven is continuously monitored with the help of three thermocouples placed at different heights (corresponding to geometry hub, midspan and tip sections). Geometry temperature will be assumed as constant once the temperature variation reading by the thermocouple is lower than $0.001 \mathrm{~K} / \mathrm{s}$. Although the prescribed techniques does not need the geometry to be at a uniform initial temperature, still, it was checked that all the aforementioned temperature fell within $10 \mathrm{~K}$ range.

- After reaching the target temperature, the mass flow rate of the coolant is set with the help of the bypass system.

- Subsequently, the oven is removed, and the mirrors are positioned quickly. Turning on the control switch (Figure 1) forces the 3-way valve to direct the coolant flow towards the geometry, and the test starts. The switch also triggers the data acquisition unit and IR camera to start recording the data (like external surface temperature, coolant mass flow rate, and its temperature) for a duration of $120 \mathrm{~s}$, which is enough to include the whole thermal transient region for all testing conditions.

\subsubsection{Data Postprocessing}

Some postprocessing will be performed on the recorded IR 2D temperature data to associate it with corresponding location on the geometry outer surface. A custom 3D methodology is set up for this purpose which links a series of marker points on the test sample to known positions of the solid model of the geometry, thus providing the $(\mathrm{x}, \mathrm{y}, \mathrm{z})$ position of every relevant point of the IR camera output.

The main purpose of the proposed methodology is to find the internal heat transfer value of the geometry. The external surface recorded 3D temperature map can be used to calculate the initial heat transfer value using LTCM for the geometry. If the geometry is approximated as a wall of thickness $l$, considering the temperature as uniform along the wall and neglecting external heat loss and side heat fluxes, the average heat flux value $q$ can be calculated using as:

$$
q=-\rho c l \frac{\triangle T_{w}}{\triangle t}
$$

where $c$ is the specific heat capacity of geometry wall material, $\rho$ is the density, and $\triangle T_{w}$ is the external surface temperature variation during the time duration $(\triangle t)$. Local Biot number $B i$ must be lower than 0.1 [18] to reliably apply this LTCM: as a result, it was worth it to confirm a posteriori if the largest $B i$ value (derived from the largest local thickness and smallest local $\mathrm{h}$ ) satisfies the said condition and the lateral gradient of the temperature.

However, to obtain a more reliable heat transfer value, it is required to set up a FEM of the geometry, which will include all the phenomena neglected by LTCM. This leads us to the second part of our methodology: finite element analysis. 


\subsection{Finite Element Analysis Part}

Transient FEM simulation is executed on the CAD model of the same geometry with same material properties, initial boundary, boundary conditions, and time duration to replicate the experiment. Initial conditions, like the initial temperature distribution, for all the nodes can be obtained by performing a steady simulation, which uses the temperature distribution measured at time $t=0$ during the experiment as external boundary condition. Keeping in the mind the strong temperature variation (range from ambient to $230^{\circ} \mathrm{C}$ ) along the test, temperature-dependent material properties, like density, specific heat capacity, and thermal conductivity, are implemented in the solver. Heat flux condition is set on the internal surface of the geometry (in which its value can be updated), while, to model the heat losses to the environment, both natural convection and radiation heat flux are imposed on the outer surface of the geometry. The value of the external convective heat transfer coefficient is retrieved from literature correlations [18], and its value is set as a constant and equal to the average along the whole test. However, it is worth it to point out that, in each case, the external heat transfer coefficient generally does not exceed $6 \%$ of the internal heat flux in the typical flow conditions for internal cooling channels in turbomachinery applications. In order to optimize the post-processing effort, the size of the computational grid in the FEM model can be defined as the one providing the lowest computational cost for which the result is not affected by grid sizing.

Now, the main objective of proposed methodology is to compute the internal heat transfer coefficient $h$ of the geometry. This can be achieved as slope of the linear relation between the wall heat flux and wall-to-flow temperature difference, as according to the Newton's law of cooling:

$$
q=h\left(T_{w}-T_{f}\right),
$$

where $q$ is the local wall heat flux, $T_{w}$ is the wall temperature, and $T_{f}$ is the adiabatic wall temperature (a wall temperature value when no heat transfer occurs [19]), representative of the local flow temperature. Different $\left(q, T_{w}-T_{f}\right)$ couples obtained at different time steps will be required for having a linear regression curve from which $h$ is determined [20].

The schematic of the proposed methodology is shown in Figure 2, where, after performing the experiment (as discussed in Section 2.1), the whole test duration is divided into $n$ time steps. The number of time steps is a trade off between two opposite requirements: the number shall be large enough to build up a robust linear relation, but the temperature drop along each time step needs to be reasonably larger than the experimental uncertainty of temperature measurement, which provides a minimum duration for the step itself. For each time step, we have to find $\left(q, T_{w}-T_{f}\right)$ couples which can be used to find $h$ using linear regression.

Considering the single time step, transient FEM model of the geometry will be run for the duration of the time step with initial internal heat $q$ obtained by LTCM. At the end of the time step, FEM will provide nodal temperatures as a result: these include the outer surface temperature of the geometry, where experimental measured temperature values are already available. It is, thus, possible to directly compare the predicted external surface temperature of FEM $\left(T_{F E M}\right)$ with experimental measured $\left(T_{E x p}\right)$ one. Given that FEM correctly represents the experiment, the local difference between $T_{F E M}$ and $T_{E x p}$ will be only related to the internal heat $q$ distribution, which can be updated to minimize this difference. The internal heat $q$ value will, thus, be continuously iterated until the convergence is achieved, i.e., until the local difference between $T_{F E M}$ and $T_{E x p}$ becomes lower than a given threshold. For updating the internal heat $q$ value, any rooting-finding algorithm can be used: for this case, the secant method was selected, given its easy implementation and quick convergence. At the end of the time step, the final internal heat $q$ and geometry wall temperature $\left(T_{w}\right)$ values are obtained. 


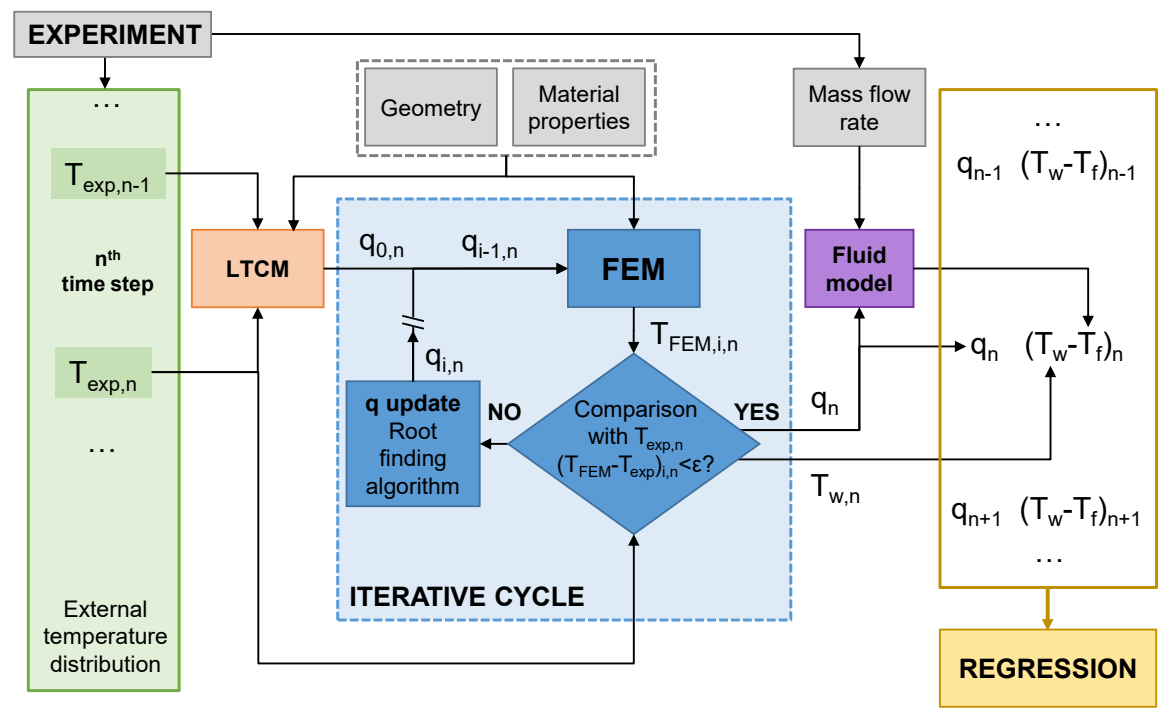

Figure 2. Schematic of the proposed methodology.

The whole procedure is repeated for all $n$ time steps to obtained $q$ and $T_{w}$ for each time step. It should be noted that, for the first time step FEM simulation, the initial temperature distribution condition is obtained from the experiment, while, later, the final output temperature of the FEM calculated at the previous time step acts as input initial temperature distribution for the next time step FEM simulation.

After procuring the $q$ and $T_{w}$ for each time step, the $T_{f}$ must be calculated. There can be two assumptions regarding flow temperature: one is as constant and the other as variable. If the flow temperature is considered constant throughout test duration, then, according to the Equation (2), plotting heat flux $q$ as function of wall-to-flow temperature or wall temperature only allows us to retrieve linear fittings having the same slope. As a result, it is possible to obtain $h$ from local heat flux $q$ and wall temperature only, since the detail of flow temperature will not be required. Moreover, by extrapolating the linear relation to zero heat flux [21], we can obtain an adiabatic wall temperature in this case. In general terms, the error introduced on $h$ estimation by considering the flow temperature to be constants along the whole time step is equal to $\triangle T_{w} / \triangle T_{f}$, which can be verified form Equation (1), e.g., the wall temperature variation needs to be at least 20 times larger than the flow to retrieve a $h$ value with less than $5 \%$ difference with respect to the correct one.

If the estimated flow temperature variation is reasonably large with respect to the wall temperature variation, then its evolution in space and time needs to be evaluated during the test. For this, a fluid model network inside the geometry cooling channel will be needed, which must provide the local flow temperature at every location by taking into consideration the inlet temperature and mass flow rate.

Since, in this case, the FEM simulation already gives heat flux values, these can be fed to this fluid model, since they correspond to energy actually transferred from the solid to fluid. Models of various complexities, from zero-dimensional model to a full transient 3D CFD can be used for this purpose. However, a simple model based upon energy balance shown in Equation (3) can provide satisfactory results in this case. The whole internal heat transfer surface can be divided into equal sectors each with single inlet and outlet, given that at every section of the geometry the coolant mass flow rate is known (Figure 3). By knowing heat flux $q$ and inlet flow temperature $T_{i n}$, energy balance allows to obtain the outlet flow temperature $T_{\text {out }}$ of each sector using the following equation:

$$
T_{\text {out }}=T_{\text {in }}+\frac{\int_{s} q d_{s}}{m c_{p}}
$$

where $S$ is the sector heat transfer surface, $m$ is the mass flow rate of the sector, and $c_{p}$ is flow specific heat capacity. To enhance flow spatial temperature resolution, the size of 
each sector can be reduced. By applying this fluid model to the whole internal surface at given time step, a bulk temperature value $T_{f}$ for the flow in every location staring from a measured inlet temperature is obtained. Subsequently, the $\left(T_{w}-T_{f}\right)$ difference is retrieved, which can thus be employed for linear regression and, thus, to calculate correct local $h$ value.

All steps of the regression procedure (Figure 2), after performing the experimental part are carried with the help of MATLAB by customized scripts, apart from the FEM analysis, which is performed with ANSYS Mechanical v18 via batch automatic execution.

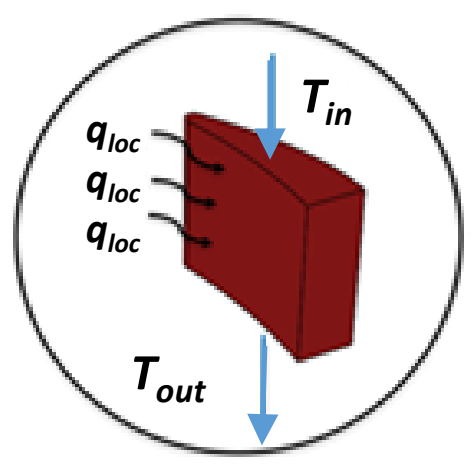

Figure 3. A sector of geometry internal surface.

\subsection{Regression vs. Baseline Technique}

As mentioned above, the regression is the modified version of the technique proposed by Nirmalan et al. [12], which will thus be referred as baseline technique. Some differences, along with pros and cons of both methods, are as follows:

- Variable of Interest: In the regression, the variable of interest is the heat flux $q$, while, in the baseline technique, it is the heat transfer coefficient $h$. These variables are continuously iterated until the convergence between the FEM and experimental external temperature is achieved.

- Fluid Model: Fluid model in the baseline techniques is coupled with FEM, while, in the regression, it is not. In the regression, the flow model is called if it is necessary (fluid temperature undergo a reasonable variation along the test) and after the implementation of the FEM. This allows to decouple the solid resolution and flow, improving the procedure stability and avoiding it to diverge if particular flow phenomena occurs (as will be exemplified in the Section 3.3).

- Temperature Comparison: The FEM and experimental temperature comparison is done at each time step in the case of regression, while, in the baseline case, at the end of the whole transient test. Dividing the test into a series of time steps in the regression allows to easily identify the time intervals which are not reliable for the analysis, since they will produce outliers in the linear relation between $q$ and $\left(T_{w}-T_{f}\right)$. In particular, based on such criterion, some points can be excluded close to the beginning of the test (when the flow is setting up and strongly transient heat transfer phenomena may occur) and approaching the end of the test (when $T_{w}$ variation becomes comparable with the experimental uncertainty).

- Noise: A disadvantage of the regression with respect to the baseline technique lies in the higher noise level in the obtained results, which is related to the lower temperature difference between the initial and final states of the single transient FEM simulations (single time step for the proposed method versus whole test for the baseline technique) and larger number of iterations.

- Computational Cost: Regression has a computational cost almost four times larger with respect to the baseline technique (Section 3.3) since it requires the computation to iteratively converge for each time step. 


\section{Investigated Geometries}

\subsection{Circular Duct}

A circular duct is selected as a baseline geometry for the implementation of the proposed methodology. The reason for selection of this geometry as baseline lies in its axial symmetrical nature and availability of the literature data. Because of the axial symmetry of the duct, heat transfer or temperature values along one axis can be representative of the remaining axes. It is a smooth circular duct made of stainless steel $(k=16 \mathrm{~W} / \mathrm{mK})$ with internal diameter $D_{\text {in }}=10 \mathrm{~mm}$, outer diameter $D_{\text {out }}=12 \mathrm{~mm}$ and $1000 \mathrm{~mm}$ length with the observing length of $230 \mathrm{~mm}$ only. Various test conditions are chosen with different Reynolds numbers $\operatorname{Re}\left(\operatorname{Re}=m D_{\text {in }} / A \mu\right.$, where $\mathrm{m}$ is the mass flow rate, $A$ is the area, and $\mu$ is the viscosity) ranging from 25,000 to 75,000 .

Different thermal transient durations are selected, dependent upon the Re number, i.e., $15 \mathrm{~s}$ for $R e=75,000,30 \mathrm{~s}$ for $R e=50,000$, and $50 \mathrm{~s}$ for $R e=25,000$, which is further divided into time steps. The obtained final results are shown below in Figure $4 \mathrm{a}$, where comparison is performed with the baseline technique and second Petukhov equation correlation [22]. The heat transfer values are taken along $\mathrm{x}$-axis only. Now, considering the average value of the heat transfer coefficient (HTC) along the duct $x$-axis, it is found that, in both regression method $\left(h \_r e g=238.82 \mathrm{~W} / \mathrm{m}^{2}{ }^{\circ} \mathrm{C}\right)$ and the baseline technique $\left(h \_b a s=244.89 \mathrm{~W} / \mathrm{m}^{2}{ }^{\circ} \mathrm{C}\right)$, the value always falls within 4 to $5 \%$ of the correlation ( $h \_$corr $=258 \mathrm{~W} / \mathrm{m}^{2}{ }^{\circ} \mathrm{C}$ ). As observed, the regression results are noisier compared to the baseline technique, but their average values are very close to each other. Tests with other $R e$ values are also performed, and the obtained results (both regression and baseline) are always within $4 \%$ to $5 \%$ of the correlation. Figure $4 \mathrm{~b}$ shows the comparison of $N u$ versus $R e$ for all tests to justify the accuracy and robustness of our result. $N u$ is retrieved using $N u=h D_{\text {in }} / k$, where $h$ is the average HTC value along the duct length. The $N u$ obtained from the regression $\left(N u \propto R e^{0.797}\right)$ is very close to the correlation and baseline technique and follows closely the trend $N u \propto R e^{0.8}$, which further proves its robustness.

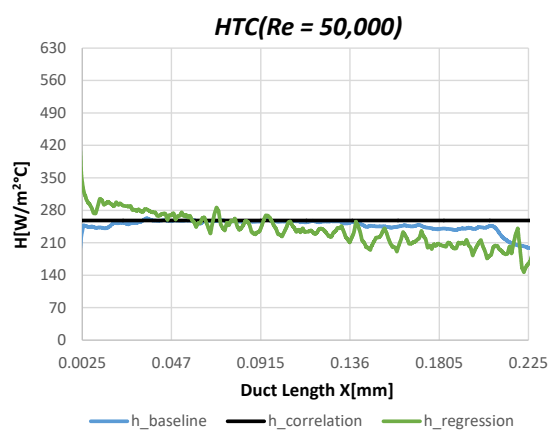

(a)

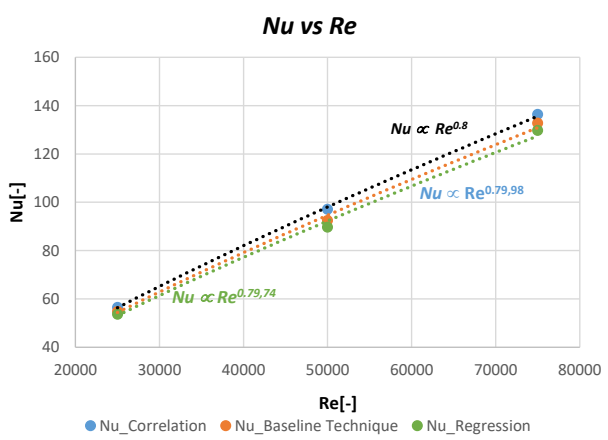

(b)

Figure 4. Heat transfer coefficient (HTC) comparison for $\operatorname{Re}=50,000^{\prime \prime}$ (a) Nu vs. $\operatorname{Re}(\mathbf{b})$.

\subsection{Mockup of Gas Turbine Blade}

A mockup of gas turbine blade with internal U-bend cooling channel, as shown in Figure $5 \mathrm{a}$, is the next geometry used for testing. It is a prismatic 3D model printed in Inconel and built by extruding the mid-span profile of a first stage rotor blade by considering a reduction scale factor of 1.5. It is provided with perforated flange which helps in fixing the article in the test rig. The characteristics of the U-bend cooling channel consists of: a smooth channel with no ribs, surface roughness of $50 \mu \mathrm{m}$ entail by used manufactured technique, and having a turning vane in the U-bend region. The U-bend region of the channel is shown in transparency to have a clear view of the coolant path which is fed through the LE channel. Different test conditions are considered with each different mass flow rate providing unique $R e$ number $\left(R e=m D_{r e f} / A \mu\right.$ : where $m$ is the mass flow rate, $D_{r e f}$ is the cooling channel hydraulic diameter assumed as reference length, $A$ is its effective area, and $\mu$ is the viscosity evaluated at the average film temperature during the test). Because 
of its non-axial symmetrical nature, a full 3D surface temperature measurement will be required during thermal transient, which is acquired with IR, two mirrors, and customized 3D mapping procedure.

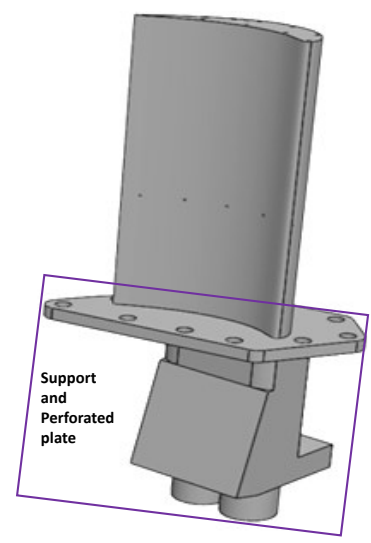

(a)

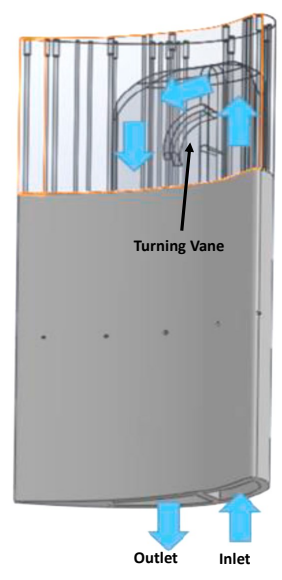

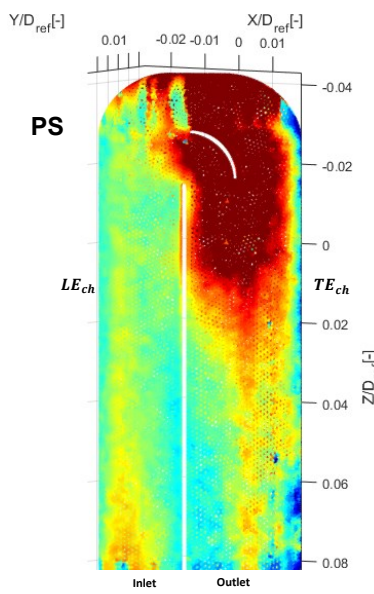

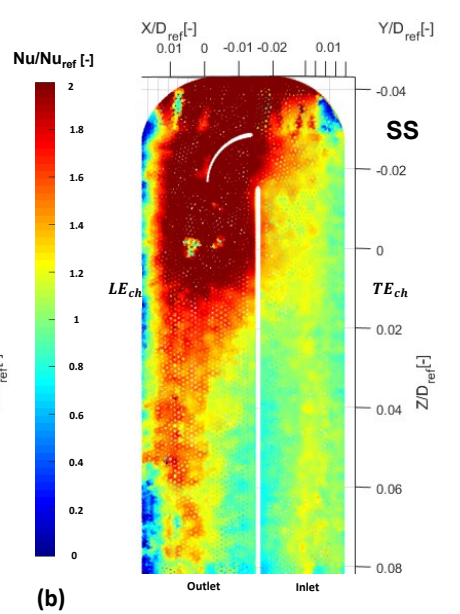

(b)

Figure 5. Blade with U-bend internal cooling channel, (a) Heat transfer distribution of internal cooling channel for pressure side (PS) and suction side (SS) for $R e=36,870$ (b).

Figure $5 \mathrm{~b}$ shows the obtained heat transfer distribution of the cooling channel section which fall inside the blade airfoil for the highest $R e=36,870$, where the obtained results are first recast in dimensionless form $N u$ using $N u=h D_{r e f} / k$ and then scaled with $N u_{r e f}$ (average $\mathrm{N} u$ value of the LE channel). Looking at the results, starting from the inlet along the LE channel $\left(L E_{c h}\right)$, the heat transfer values are uniform till the U-bend region of the channel. The values in the top of the channel are higher, which may be due to flow impingement in this region.

As we move along the U-bend region, the presence of turning vane further enhances the heat transfer values by increasing the flow velocity, and this effect is also prolonged to $T E_{c h}$ top region. After that, the heat transfer values become uniform and almost similar to the $L E_{c h}$. Lower heat transfer values are observed in $T E_{c h}$ : in the region closer to the blade $\mathrm{TE}$, which can be attributed to the wedge shape of the blade.

The relative difference between the regression and baseline technique $\left(\delta=\left(\left(N u_{\text {Regression }}-N u_{\text {Baseline }}\right) / N u_{\text {Baseline }}\right)\right)$ is highlighted in the Figure 6. In both techniques, the heat transfer distribution pattern resembles to each other: uniform at the $L E_{c h}$, then increase in the U-bend region, and again are uniform in the $T E_{c h}$. Both methods provides similar values with local difference not exceeding $\pm 15 \%$ concerning the $L E_{c h}$ and larger portion of $T E_{c h}$ and U-band. Higher difference is seen at top of the U-band and $T E_{c h}$ close to the blade TE, owing to the noisier results provided by the regression.

Figure 7 shows the comparison of the obtained results with correlation for all test cases [22] by assuming the section of the $L E_{c h}$ preceding the U-band as a circular straight duct. In particular, the obtained results are averaged over a stream-wise section far enough from the duct inlet and U-band to hypothesize that a fully developed flow is present (as shown by the black rectangle in the Figure 7). By inspecting the figure, it can be concluded that the result obtained from regression is always within $4 \%$ to $5 \%$ to the baseline and correlation ones and follows the trend $N u \propto R e^{0.8405}$, which further prove its robustness.

Uncertainty analysis can be done here by supposing a single input parameter uncertainty as shown in the Table 1, performing sensitivity of the outcome [14,23], and, finally, adding all contributions using a quadratic error propagation model (Equation (4)) to estimate the global error on $\mathrm{Nu}$ related to each input.

$$
\varepsilon_{\text {tot }}=\sqrt{\left(\varepsilon_{1}^{2}\right)+\left(\varepsilon_{2}^{2}\right)+\left(\varepsilon_{3}^{2}\right)+\ldots+\left(\varepsilon_{n}^{2}\right)}
$$


where $\varepsilon_{i}$ represents the relative uncertainty associated with each parameter and $\varepsilon_{\text {tot }}$ is the overall uncertainty. In Figure 8, a sample outcome for $R e=36,870$ of such analysis is shown where average uncertainty of $5 \%$ to $7 \%$ is observed both on $L E_{c h}$ and $T E_{c h}$. The value increases up to $15 \%$ at the lower passage area specially on $T E_{c h}$ of the blade because of the higher effect of the external $h$ on the heat transfer and noisier results in this region.
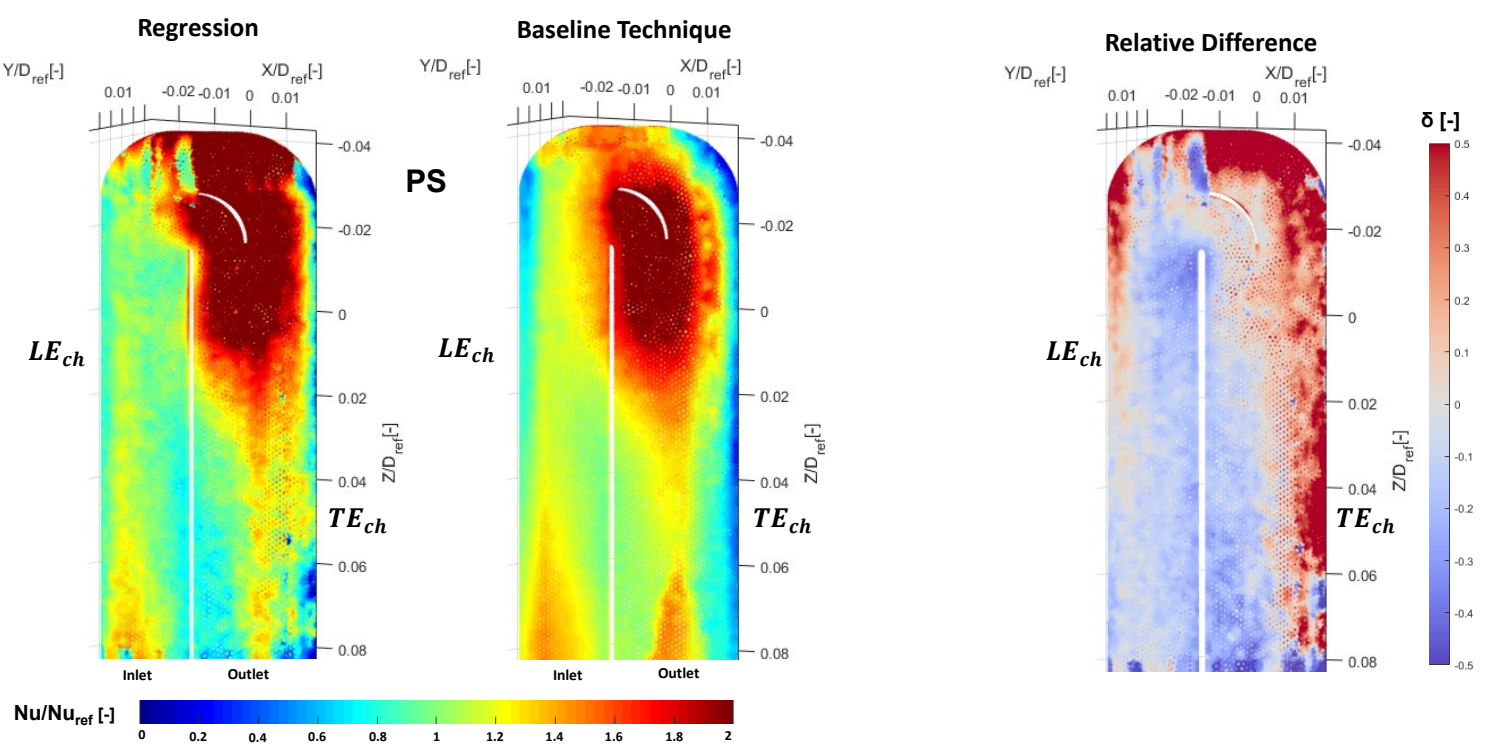

Figure 6. Heat transfer distribution obtained with regression and baseline and their relative difference.

\subsection{High Pressure Vane}

To demonstrate the applicability of the regression on a real complex hardware for retrieving its heat transfer information, a cooled high pressure vane of a real engine is selected. The airfoil shape is strongly 3D with filleted and curved surfaces and an articulate internal cooling scheme: as a result, the regression is particularly suitable to measure its heat transfer features as respect to the previous models. The typical features of the internal cooling system of a high pressure gas turbine vane are present in the chosen geometry (more details about the geometry can be found in Reference [24]). First, the coolant enters the system close to the LE and feeds a perforated plenum, which covers the whole frontal part of the airfoil (impingement box at LE): the holes generate a series of jets which cool down the inner side of the blade surface. Then, the spent cooling flow leaves this region in axial direction to enter a battery of fin pins present in the midchord region of the airfoil. After that, the air flows in series of axial ducts and is finally discharged out of the airfoil through holes on the PS close to the TE.

Different test parameters are selected in order to replicate the typical working conditions of high pressure gas turbine vane. In order to find the suitability of the technique with various operational conditions, different coolant mass flow rates are investigated. For each coolant mass flow rate, $R e$ is calculated by $R e=m_{\text {tot }} d_{i m} / A_{\text {tot }} \mu$, where $m_{\text {tot }}$ is the overall mass flow rate, $d_{i m}$ is the diameter of the impingement hole, $A_{\text {tot }}$ is the overall impingement passage area, and $\mu$ is the air dynamics viscosity. It is worth it to note that operation conditions are scaled at ambient pressure with moderate temperature results in losing the Mach number similitude. It means that, in some regions of the blade, the Mach number could be higher in the experiment's respect to the engine. 

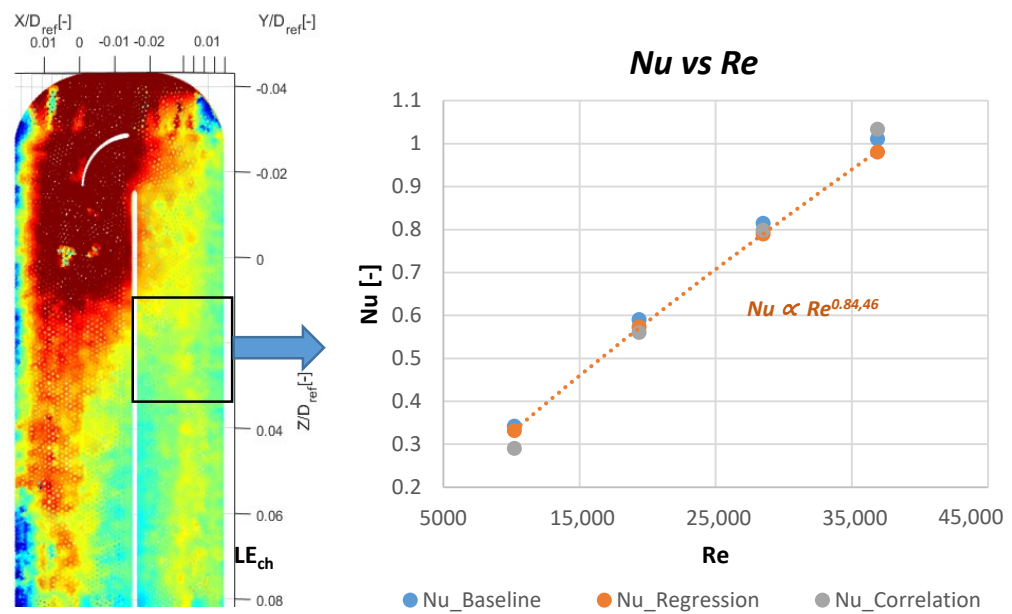

Figure 7. Comparison of the regression results with baseline and correlation for selected $L E_{c h}$ rectangular region.

Table 1. Contribution to the uncertainty on $\mathrm{Nu}$.

\begin{tabular}{cccc}
\hline \multirow{2}{*}{ Parameter } & \multirow{2}{*}{ Uncertainty } & \multicolumn{2}{c}{ Typical Contribution to Nu Uncertainty } \\
\cline { 3 - 4 } & & LE Region & TE Region \\
\hline$T_{w}$ & $0.6 \mathrm{~K}$ & $4 \%$ & $3.5 \%$ \\
$T_{f_{\text {in }}}$ & $0.6 \mathrm{~K}$ & $0.75 \%$ & $0.75 \%$ \\
$k$ & $5 \%$ & $4.5 \%$ & $4 \%$ \\
$m$ & $0.5 \%$ & $0.5 \%$ & $1 \%$ \\
$h_{\text {ext }}$ & $15 \%$ & $4 \%$ & $5 \%$ \\
$\rho c$ & $5 \%$ & $4 \%$ & $4 \%$ \\
$t$ & $0.5 \mathrm{~s}$ & $3 \%$ & $2 \%$ \\
\hline
\end{tabular}

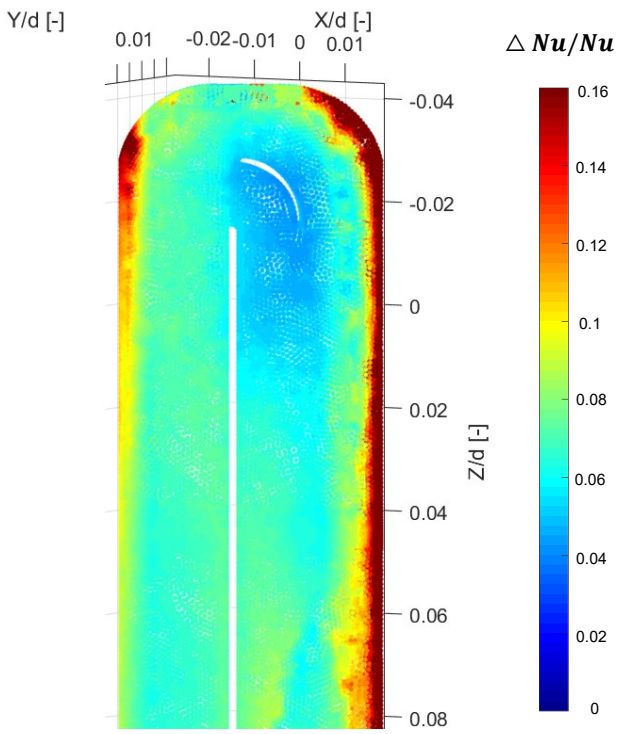

Figure 8. Local uncertainty for $R e=36,870$.

Figure 9 shows the obtained final results considering the highest $\operatorname{Re}$ value (8138) after the implementation of the regression methodology for the vane. Results are recast into the dimensionless form of $\mathrm{Nu}$ and scaled with average value of $\mathrm{Nu}$ at $\mathrm{LE}$ region $\left(N u_{r e f}\right)$. Some airfoil regions are highlighted with gray color as shown in Figure 9 because, by using the current setup, a reliable measurement of the surface temperature is available only on the airfoil, while no such useful data is available neither for hub and tip platform, nor for the 
the filleted regions connecting platform to the airfoil. In addition, the terminal part of TE is excluded for the reason that, in this region, the heat transfer will be affected by spurious effect (i.e., forced external convection related to the entrainment of the surroundings air).

By examining the achieved results, different magnitude and pattern of the heat transfer values are noted, linked with different features of the internal cooling system with a reasonable resolution. At the LE region, the highest heat transfer values are seen on the thin area aligned with axis of the airfoil, located near the actual LE of the airfoil itself. This increase of the heat transfer can be associated with the fact that the impingement jets are not affected by cross flow [25] in this region. Considering the same assumption, the heat transfer values monotonically decrease as we move towards the TE up to half nozzle chord because the impingement jets are expected to be deflected by the upstream cross flow which grows stronger along the discharge direction. This phenomenon is the possible explanation to the fact that heat transfer values on the PS side are higher as compared to SS. Starting from the highest heat transfer value of the LE region and moving along the airfoil internal surface, a longer path is required to reach the midchord region passing from SS as compared to PS, which may lead to a stronger crossflow effect on the jets.

Moving ahead, a decrease of heat transfer values is seen in the region between the impingement and pin fin, which may be attributed to the absence of turbulence promoters and enlargement of the passage section. A different trend is observed in the pin fin region: heat transfer value increases moving towards the TE, most likely due to the converging shape of the airfoil which progressively lowers the passage area and thus increases the flow velocities. Even in the airfoil TE, this trend is confirmed where the highest heat transfer values are recorded.

Quantitative comparison between the regression and baseline technique results (considering the highest $R e$ value) is shown in the Figure 10, where the relative difference is calculated as $\delta=\left(\left(N u_{\text {Regression }}-N u_{\text {Baseline }}\right) / N u_{\text {Baseline }}\right)$. In the central part of the LE region ( where flow temperature is mainly driven by convective heat transfer), both methods provide similar results with local difference not exceeding $15 \%$, while larger discrepancies are observed towards the TE, with local difference continuously increasing up to value of $100 \%$ ( the baseline result is almost double the regression result). The reason for such large discrepancy is the failure of the baseline technique to converge: similar wall and fluid temperature values are predicted, which forces the local $h$ to increase progressively with each iteration, eventually leading to unphysical heat transfer values or even to the divergence of the procedure. This is avoided in the regression, where the fluid model is decoupled from the FEM simulation and is only fed by the step-by-step $q$ values, which, in turn, are driven by the local temperature decrease of the wall material. Moreover, it should be noted that, in the regression, the correct local $h$ estimation strictly depends on the capability of the fluid model to predict the rate of evolution of the $T_{f}$ with respect to $T_{w}$, while knowing the $q(t)$ and $T_{w}(t)$ from the FEM simulation and IR measurement. From the fluid model Equation (3), it is perceived that this last derivative term $\left(d T_{f} / d T_{w}\right)$ depends only on the mass flow distribution along the internal cooling channel (m. $c_{p}$ distribution). Consequently, the proposed method is capable of dampening the effect of a constant offset in $T_{f}$ estimation (induced for example by local recovery or expansion phenomena or by the estimation of initial fluid temperature along the channel), thus providing physically meaningful results in the present case. 

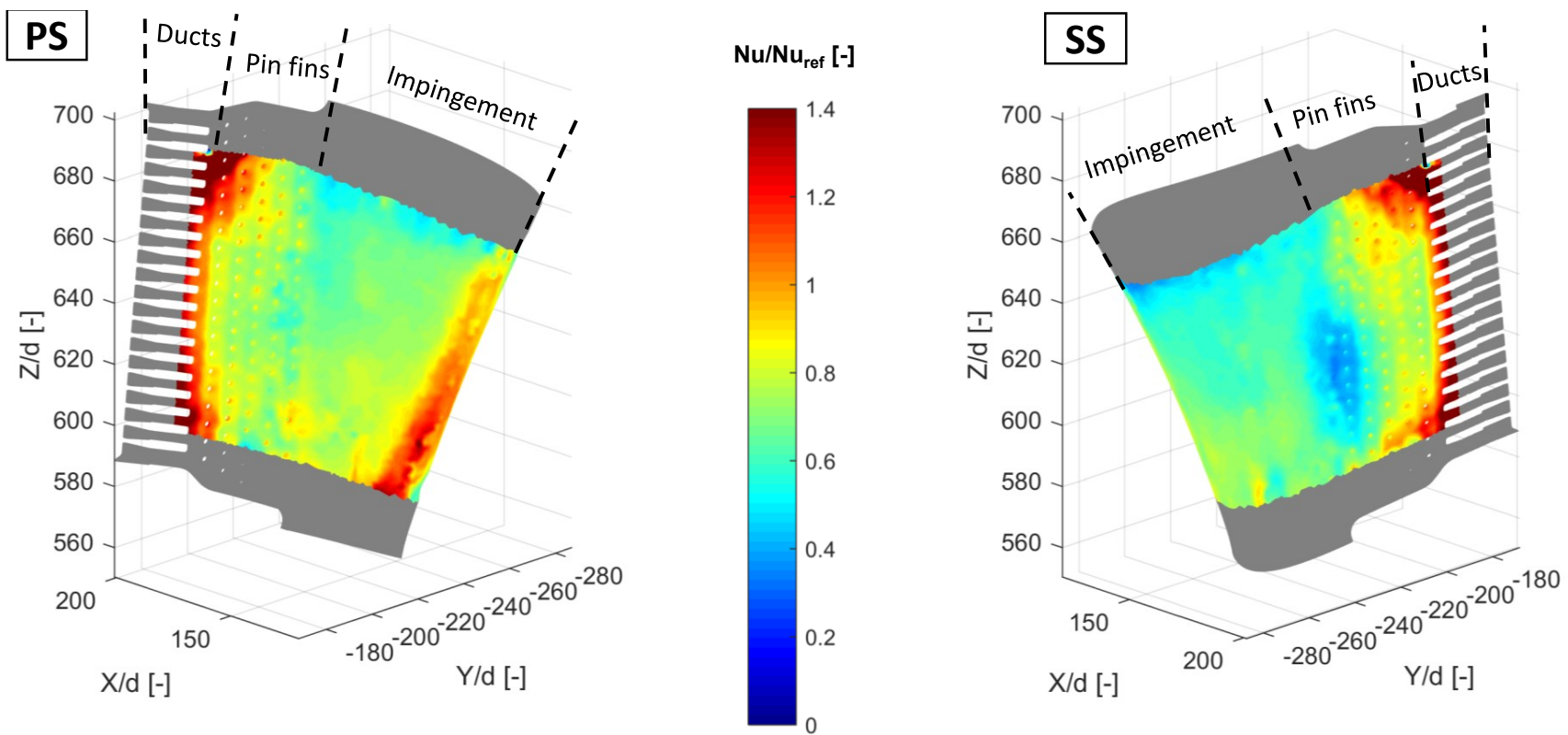

Figure 9. Heat transfer distribution obtained by linear regression methodology for the maximum $\operatorname{Re}$ value.
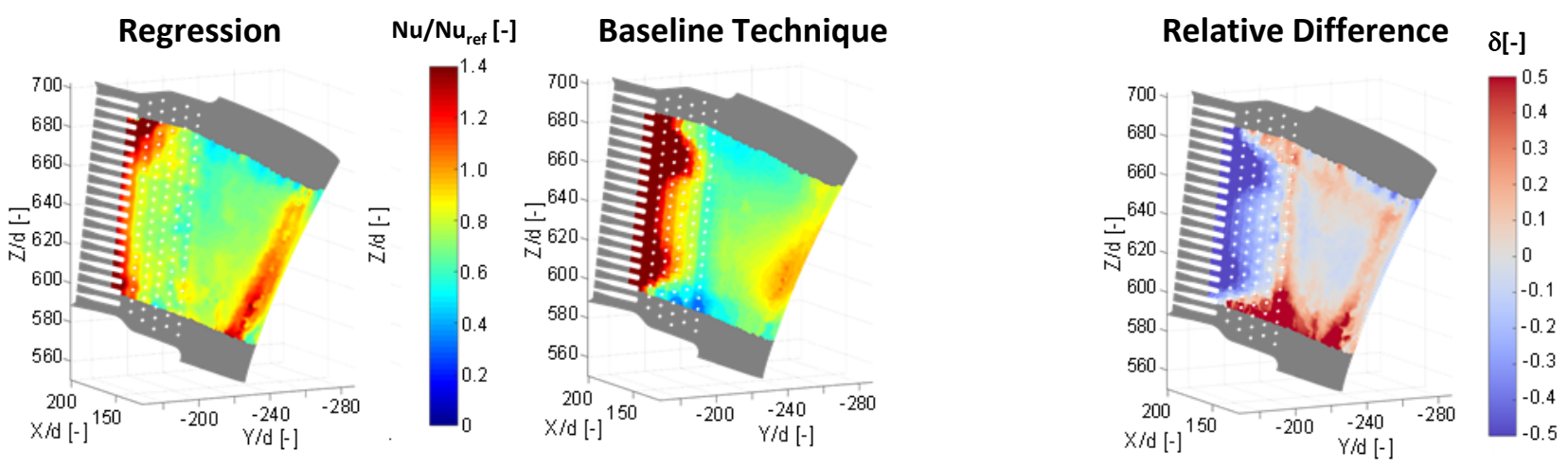

Figure 10. Heat transfer distribution obtained by the regression and the baseline technique and relative difference for the maximum Re value.

Viewing the hub and tip region shows that the regression provides more uniform heat transfer values as compared to the baseline. Regression results are less affected by the hub and tip platforms, while, in the baseline case, its presence can be associated with lower heat transfer values (up to $50 \%$ lower than the regression) near the upper and lower side of the airfoil. Baseline technique has an advantage over the regression if noise is considered: the local value is up to $20 \%$ different from the average ones on the corresponding region. The main cause of the larger noise of the regression method is actually the bigger number of iterations required with respect to the baseline technique, since convergence needs to be reached for every time step in which the test duration is divided: since every simulation starts from the outcomes of the previous one, the experimental noise is amplified if more iterations are required. This issue could be addressed either by using a smaller number of time steps (however, losing some data related to temperature evolution) or minimizing measurement noise (e.g., improving paint quality or reducing IR camera signal-to-noise ratio).

The reliability of the obtained results can be assessed by comparing the expected heat transfer values gained from literature data. In this case, BANKS solver is used for modeling the internal cooling network, details of which can be found in Reference [26,27], and has the capability to implement different correlations related to each cooling system feature from the open literature. Figure 11 (left) shows the direct local comparison of the regression 
(REG) and correlation (CORR) results on the airfoil internal surface, obtained as explained above for $R e=6145$.

The heat transfer distributions of both regression and correlation provide a very similar pattern (Figure 11 (left)). Higher values are seen on the LE, which then decrease towards TE till nozzle midchord region both on PS and SS. Finally, on the pin fin regio, an increasing trend is provided by both, although the size of growth in the regression case is larger. A direct quantitative comparison can be performed if heat transfer values are compared on some specific points shown in Figure 11 (left). The charts in the Figure 11 (right) reveal a reasonable agreement of regression, baseline (BASE) and correlation on various locations, like point 1 , point 2 , and point 4 , throughout the whole investigating Re range. But, on the point 3 closer to the TE, the agreement seems to depend upon the $R e$ value the results diverge from each other as $R e$ value increases. In the case of baseline technique, the values are higher as compared to the regression and correlation because, in this region, it fails to converge, as already mentioned in above passage.
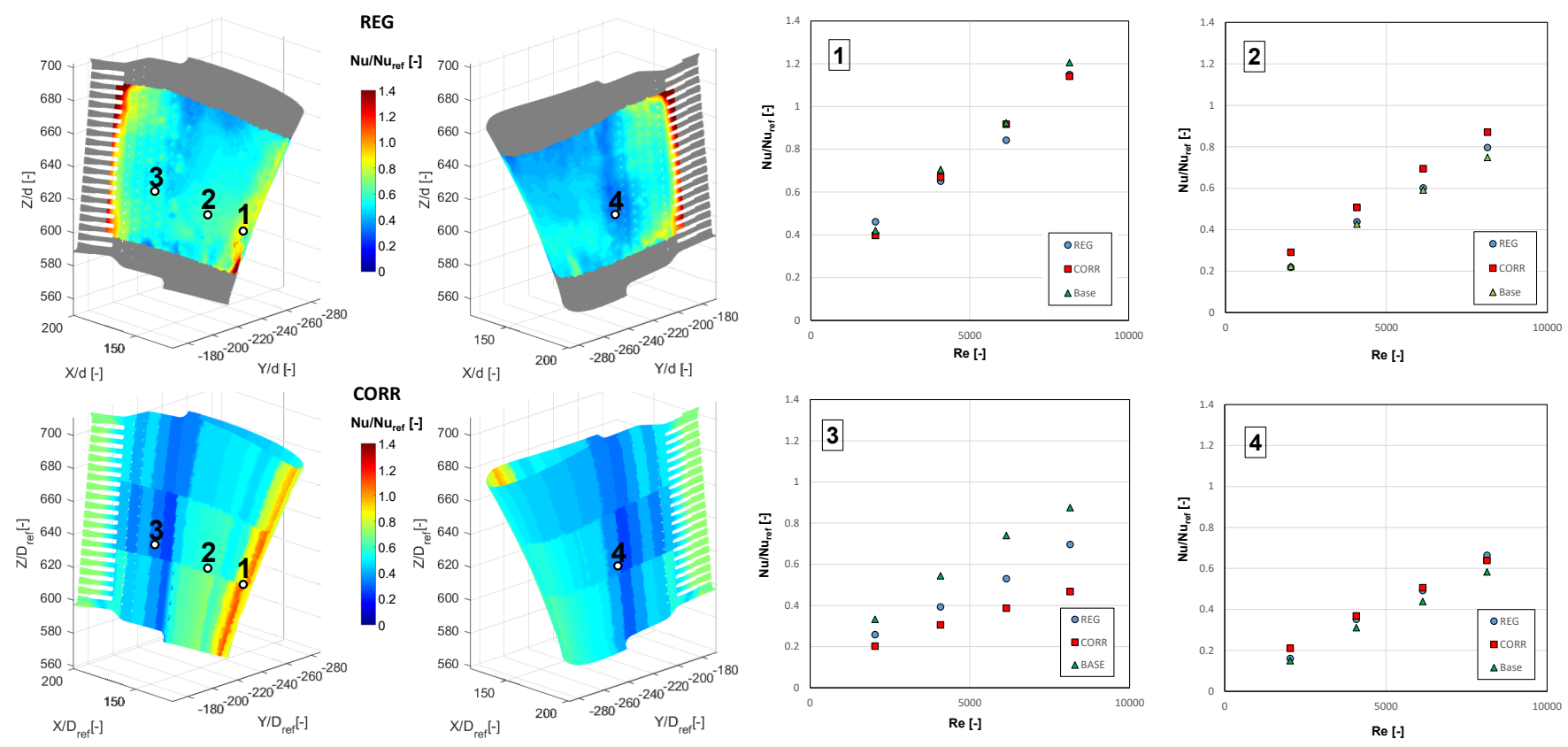

Figure 11. Comparison of regression and correlation for the $R e=6145$.

While a possible reason for the discrepancy between regression and correlation can be connected to the compressibility effects, which are likely to occur in these regions, in fact, as already mentioned, large Mach number values may be present in the final part of the cooling system, which may affect the air temperature evolution and thus alter the measurement in this region. While this effect of flow Mach number is not considered in the employed correlations, results into heat transfer values may not be totally reliable in these conditions. This interpretation is confirmed by the fact that the agreement is better for low values, where lower Mach numbers and, thus, less intense compressibility effects are expected.

Finally, an uncertainty analysis was also performed following the same approach described in Section 3.2. The single contributions to overall uncertainty are summarized in Table 2 for both the leading and trailing edge regions. It can be noticed that, in the leading edge region, the single contributions to uncertainty are similar to the ones obtained in the U-bend case, apart from the contribution of mass flow rate, which is null since, in this region, the application of the fluid model is not required. This provides a typical uncertainty around $7-8 \%$. On the other hand, for the trailing edge region the contribution of material properties significantly grows (due to the relative small size of the cooling system with respect to the metallic airfoil). The contribution of both mass flow rate and 
inlet flow temperature also increases, due to the amplification of these uncertainties along the fluid model applied for the whole complex cooling system. As a consequence, local uncertainty values up to $20 \%$ are obtained for the trailing edge region in this case.

Table 2. Contribution to the uncertainty on $N u$ for Vane.

\begin{tabular}{cccc}
\hline \multirow{2}{*}{ Parameter } & Uncertainty & \multicolumn{2}{c}{ Typical Contribution to Nu Uncertainty } \\
\cline { 3 - 4 } & & LE Region & TE Region \\
\hline$T_{w}$ & $0.6 \mathrm{~K}$ & $3 \%$ & $5 \%$ \\
$T_{f_{i n}}$ & $0.6 \mathrm{~K}$ & $0.5 \%$ & $2 \%$ \\
$k$ & $5 \%$ & $2 \%$ & $2 \%$ \\
$m$ & $0.5 \%$ & - & $8 \%$ \\
$h_{e x t}$ & $15 \%$ & $4 \%$ & $4 \%$ \\
$\rho c$ & $5 \%$ & $5 \%$ & $15 \%$ \\
$t$ & $0.5 \mathrm{~s}$ & $0.8 \%$ & $3 \%$ \\
\hline
\end{tabular}

\section{Conclusions}

Regression methodology, a modified version of the one already presented by Nirmalan et al. [12], was developed in this work for the measurement of internal heat transfer of real cooled geometry. It consists of the induction of a controlled thermal transient for a cooled geometry by heating it to a known temperature and then injecting coolant and recording the external surface temperature evolution by a IR camera. The procured data is then used by a transient FEM procedure, in which its main objective is to find the time-dependent internal heat flux $q$ and wall temperature $T_{w}$ distributions in order to obtain the same external temperature as the experiment. The flow temperature variations along the test are calculated using a fluid model when it is relevant. Finally, the heat transfer coefficient values are retrieved via linear regression using $\left(q, T_{w}-T_{f}\right)$ couples at different time steps.

Three different geometries (a circular duct, a mockup of gas turbine blade, and high pressure vane of real engine) are selected to assess the suitability of the technique for the measurement of heat transfer distribution. In each case, the proposed method provides detailed heat transfer distributions on the internal cooling channel surface considering different coolant mass flow rates. The values are always in line with the expected ones. The method also shows superior stability and physical significance as compared to similar approaches in the case of complex and difficult to model flow phenomena.

On the base of the retrieved results, it can be concluded that the regression methodology will be suitable for investigating complex internal cooled real geometries.

Author Contributions: A.A., L.C. and A.P. conceived and designed the experiments. A.A. and L.C. carried out the experiments and analyzed the data. A.A. wrote the paper. B.F. supervised the whole process and checked the paper. All authors have read and agreed to the published version of the manuscript.

Funding: This work carried out in the framework of the STech program. Regione Toscana was the co-funder of the STech 'Smart Technologies' program 2017-2019 (FAR-FAS 2014 public notice).

Institutional Review Board Statement: Not Applicable.

Informed Consent Statement: Not Applicable.

Data Availability Statement: Experimental data sharing is restricted by specific agreements between the authors and the private companies owning the investigated geometries. The code employed for the postprocessing of the experimental data is available upon request from the corresponding author.

Acknowledgments: Regione Toscana is thankfully acknowledged for the possibility to carry and publish the present work. 
Conflicts of Interest: The authors declare no conflict of interest. The funders had no direct role in the collection, analyses, or interpretation of data; in the writing of the manuscript, or in the decision to publish the results.

\section{Abbreviations}

The following abbreviations are used in this manuscript:

\begin{tabular}{ll}
\multicolumn{2}{l}{ Acronyms } \\
FEM & Finite Element Model \\
IR & Infrared camera \\
LTCM Lumped thermal Capacitance Model \\
LE $\quad$ Leading edge \\
PS $\quad$ Pressure side \\
SS $\quad$ Suction side \\
TLC & Thermochromic Liquid Crystals \\
TE & Tailing edge \\
CFD & Computational Fluid Dynamics \\
Subscripts \\
$\mathrm{f}$ & fluid \\
i & iteration number \\
in & Inlet \\
$\mathrm{n}$ & Time step number \\
out & outlet \\
ref & Average of LE region \\
tot & overall \\
w & wall \\
$\mathrm{s}$ & sector surface
\end{tabular}

\section{Nomenclature}

$\begin{array}{lll}\mathrm{A} & \text { Passage area } & {\left[\mathrm{m}^{2}\right]} \\ \mathrm{Bi} & \text { Biot number } & {[-]} \\ \mathrm{C} & \text { Specific heat capacity } & {\left[\mathrm{J} \mathrm{kg}_{-1} \mathrm{~K}^{-1}\right]} \\ D_{\text {im }} & \text { Impingement hole diameter } & {[\mathrm{m}]} \\ \mathrm{h} & \text { Convective heat transfer coefficient } & {\left[\mathrm{W} \mathrm{m}^{-2} \mathrm{~K}^{-1}\right]} \\ \mathrm{k} & \text { Thermal conductivity } & {\left[\mathrm{W} \mathrm{m}^{-1} \mathrm{~K}^{-1}\right]} \\ \mathrm{l} & \text { Local wall thickness } & {[\mathrm{m}]} \\ \mathrm{m} & \text { Mass flow rate } & {\left[\mathrm{kg} \mathrm{s}^{-1}\right]} \\ \mathrm{Nu} & \text { Nusselt number } & {[-]} \\ \mathrm{q} & \text { specific heat flux } & {\left[\mathrm{W} \mathrm{m}^{-2}\right]} \\ \mathrm{Re} & \text { Reynolds number } & {[-]} \\ \mathrm{S} & \text { surface } & {\left[\mathrm{m}_{2}\right]} \\ \mathrm{T} & \text { temperature } & {[\mathrm{K}]} \\ \mathrm{t} & \text { time } & {[\mathrm{s}]} \\ \mathrm{Greeks} & \\ \delta & \text { Relative difference } & {[-]} \\ \varepsilon & \text { Relative uncertainty } & {[-]} \\ \mu & \text { Dynamic viscosity } & {[\mathrm{Pa} \mathrm{s}]} \\ \rho & \text { Density } & {\left[\mathrm{kg} \mathrm{m}^{-3}\right]}\end{array}$

\section{References}

1. Han, J.C.; Huh, M. TURBINE-09. In Proceedings of the International Symposium on Heat Transfer in Gas Turbine Systems; Begel House Inc.: New York, NY, USA, 2009.

2. Han, J.C.; Dutta, S.; Ekkad, S. Gas Turbine Heat Transfer and Cooling Technology; CRC Press: Boca Raton, FL, USA, 2012.

3. Webb, R.L.; Kim, N.Y. Enhanced Heat Transfer; Taylor and Francis: New York, NY, USA, 2009.

4. Stimpson, C.K.; Snyder, J.C.; Thole, K.A.; Mongillo, D. Roughness effects on flow and heat transfer for additively manufactured channels. J. Turbomach. 2016, 138, 051008. [CrossRef]

5. Von Wolfersdorf, J.; Weig, B.; Coletti, F.; Arts, T. Turbine Blade Internal Cooling-Selected Experimental Approaches; VKI Lecture Series; LS, Von Karman Institute for Fluid Dynamics: Saint-Heines-Rod, Belgium, 2010.

6. Werschnik, H.; Hilgert, J.; Wilhelm, M.; Bruschewski, M.; Schiffer, H.P. Influence of combustor swirl on endwall heat transfer and film cooling effectiveness at the large scale turbine rig. J. Turbomach. 2017, 139, 081007. [CrossRef]

7. Qureshi, I.; Beretta, A.; Chana, K.; Povey, T. Effect of aggressive inlet swirl on heat transfer and aerodynamics in an unshrouded transonic HP turbine. J. Turbomach. 2010, 134, 1457-1469.

8. $\quad$ Bantel, T.E.; Mack, D.C. Cooling Hole Inspection. U.S. Patent 4,644,162, 7 February 1987.

9. Bantel, T.E.; Mack, D.C. Apparatus and Method for Inspecting Cooling Holes. U.S. Patent 5,111,046, 5 May 1992.

10. Beckeiz, E.; Sperling, A.; Carl, V. Thermography Inspection System for Gas Turbine Blades. In Proceedings of the 7th ECNDT, Copenhagen, Broendby, Denmark, 26-29 May 1998.

11. Stiglich, J.J.; Bishop, C.C.; Eelkema, T.E.; Boone, D.H.; Daleo, J. The thermal inertia analysis technique in gas turbine component reliability assessment. Mater. Solut. 1998, 98, 138-144.

12. Nirmalan, N.V.; Bunker, R.S.; Hedlund, C.R. The measurement of full-surface internal heat transfer coefficients for turbine airfoils using a nondestructive thermal inertia technique. J. Turbomach. 2003, 125, 83-89. [CrossRef]

13. Bunker, R.S.; Osgood, S.J.; Nirmalan, N.V. The Determination of In-Situ Film Hole Flow Rates Using a Transient Thermal Inertia Method. Turbo Expo Power Land Sea Air 2003, 36886, 443-450.

14. Heidrich, P.; von Wolfersdorf, J.; Schnieder, M. Experimental Study of Internal Heat Transfer Coefficients in a Rectangular, Ribbed Channel Using a Non-Invasive, Non-Destructive, Transient Inverse Method. Turbo Expo Power Land Sea Air 2009, 43147, $275-286$.

15. Egger, C.; Wolfersdorf, J.V.; Schnieder, M. Heat transfer measurements in an internal cooling system using a transient technique with infrared thermography. J. Turbomach. 2013, 135, 447-457. [CrossRef]

16. Christensen, L.E.; Mathison, R.M. Measurement of Heat Transfer Inside a Channel Using External Infrared Thermography. Jt. Propuls. Conf. 2018, 4430.

17. Carlomagno, G.M.; Cardone, G. Infrared thermography for convective heat transfer measurements. Exp. Fluids. 2010, 49, 1187-1218. [CrossRef] 
18. Bergman, T.L.; Incropera, F.P.; DeWitt, D.P.; Lavine, A.S. Fundamentals of Heat and Mass Transfer; John Wiley \& Sons: Hoboken, NJ, USA, 2011.

19. Moffat, R.J. What's new in convective heat transfer? J. Int. Heat Fluid Flow 1988, 19, 90-101 [CrossRef]

20. Gritsch, M.; Baldauf, S.; Martiny, M.; Schulz, A.; Wittig, S. The superposition approach to local heat transfer coefficients in high density ratio film cooling flows. Turbo Expo Power Land Sea Air 1999, 78606, V003T01A048.

21. Rogers, N.; Ren, Z.; Buzzard, W.; Sweeney, B.; Tinker, N.; Ligrani, P.; Hollingsworth, K.; Liberatore, F.; Patel, R.; Moon, H.K. Effects of Double Wall Cooling Configuration and Conditions on Performance of Full Coverage Effusion Cooling. Turbo Expo Power Land Sea Air 2016, 49781, V05AT13A005.

22. Petukhov, B.S. Heat transfer and friction in turbulent pipe flow with variable physical properties. Adv. Heat Transf. 1970, 6, i565.

23. Kinell, M.; Utriainen, E.; Jaksch, P. An Alternative Experimental Method for Establishing Detailed Internal Heat Transfer Coefficient Distributions of Complex Cooling Geometries Using IR Thermography. Turbo Expo Power Land Sea Air 2014, 45714, V05AT12A018.

24. Ali, A.; Cocchi, L.; Picchi, A.; Facchini, B.; Cubeda, S. Development and application of an internal heat-transfer measurement technique for cooled real engine components. In Proceedings of the ASME Turbo Expo, London, UK, 21-25 September 2020.

25. Florschuetz, L.W.; Truman, C.R.; Metzger, D.E. Streamwise flow and heat transfer distributions for jet array impingement with crossflow. Turbo Expo Power Land Sea Air 1981, 79634, V003T09A005.

26. Andrei, L.; Andreini, A.; Facchini, B.; Winchler, L.A. Decoupled CHT procedure: Application and validation on a gas turbine vane with different cooling configurations. Energy Procedia 2014, 45, 1087-1096. [CrossRef]

27. Winchler, L.; Andreini, A.; Facchini, B.; Andrei, L.; Bonini, A.; Innocenti, L. Conjugate heat transfer methodology for thermal design and verification of gas turbine cooled components. Turbo Expo Power Land Sea Air 2018, 51081, V05AT10A001. 